\title{
Comparing the post-WWII publication histories of oceanography and marine geoscience
}

\author{
Neil C. Mitchell ${ }^{1}$ D \\ Received: 10 September 2018 / Published online: 26 May 2020 \\ (c) The Author(s) 2020
}

\begin{abstract}
Oceanography and marine geosciences are closely related subjects, though they have had differing influences. The UK, which has experienced the financial benefits of North Sea oil and gas, while also having an extensive fishing industry and a science base linked to other English-speaking countries and European countries, potentially illustrates some changing influences and collaborative tendencies well. In this article, differences in article publication rates and collaborative tendencies, both globally and for the UK, are examined using the Web of Science ${ }^{\mathrm{TM}}$, Scopus ${ }^{\mathrm{TM}}$ and Georef ${ }^{\mathrm{TM}}$ for the period 1946-2018. The results show that publication rates of global oceanography articles rose exponentially faster than all global scientific publishing from the mid-1960s to 1980. Subsequently, the exponential rate of increase slowed though has remained faster than global science publishing. Global Marine Geoscience publication rates increased into the late 1980s, but have since declined. UK oceanography has roughly followed global trends, though its share of global oceanographic publishing declined from $28 \%$ in the 1950s to $8 \%$ in 2018. UK Marine Geoscience publishing has also generally followed global trends for that field. However, its share of global publications abruptly increased from $4.9 \%$ (average 1960-1980) to $13.2 \%$ by 1990, largely due to articles arising from UK participation in the Deep-Sea Drilling Project and Ocean Drilling Program. Oceanography and marine geoscience have also experienced strongly differing histories of collaborative articles over the last four decades. While oceanographic articles co-authored with researchers in other countries have been steadily increasing as a share of total UK Oceanography articles, those of marine geoscience peaked in 1990 and have since declined, though remained at high levels similar to those experienced by 2018 in Oceanography. Comparing global publication rates in both fields with measures of data and sample collection at sea suggests fundamental changes occurred in the way research was carried out. For example, Marine Geoscience publication rates were strongly correlated with geophysical track-line distances for the decade until $\sim 1970$, but were inversely correlated for the decade after then. This reflects, for example, the development of plate tectonics, which partly involved analysis of existing marine geophysical data, improved equipment capabilities and the increased role of scientific drilling.
\end{abstract}

Electronic supplementary material The online version of this article (https://doi.org/10.1007/s1119 2-020-03498-2) contains supplementary material, which is available to authorized users.

Extended author information available on the last page of the article 
Keywords Marine science - Oceanography - Marine geology and geophysics - Marine geoscience $\cdot$ Cold War $\cdot$ Resources $\cdot$ Bibliometrics $\cdot$ Research funding

\section{Introduction}

This article considers two areas of the marine sciences as largely distinct from each other. "Oceanography" here encompasses chemical, physical, geological and biological oceanography, marine fisheries and marine engineering, whereas "Marine Geoscience" encompasses geological oceanography, basin analysis within the oceans (geology and geophysics of structures beneath the shallow sediments) and research on estuaries. These two areas have had somewhat different influences. For example, interest in the oceans as a source of food likely affected decisions of funding for Oceanography. Decisions on funding for marine geosciences, on the other hand, may have partly considered the oceans as a potential source of commodities such as oil and gas, aggregates for construction and metallic ores (Summerhayes 1998). Deep-sea metallic ores have been known to exist since the 19th Century (Riley and Sinhaseni 1958) and more recently have attracted interest as a source of rare metals (Hein and Koschinsky 2014). Societal interest in climate change and environmental conservation has likely encouraged support for research in both marine science areas more recently, though to differing degrees.

During the Cold War shortly following World War II (WWII) until the Glasnost era initiated by USSR President Gorbachev in the mid- to late-1980s, the need to understand many aspects of the oceans strongly favored oceanographic research for military purposes (e.g., Raitt and Mouton 1967). Marine Geoscience was also financially supported, given the need to understand substrate conditions, low-frequency acoustics and bathymetry for navigation. However, towards the end of the Cold War, security concerns began to recede and other influences likely exerted themselves more significantly. Those changes, variations in the prices of commodities and other factors, including broader social attitudes, are likely to have influenced the two science areas differently.

A purpose of this article is to isolate changes with time in publication rates of these two fields to see if the timings of those changes can be related to identifiable influences. Publication rates of articles produced by UK-based researchers are also derived as, besides being interesting for the peculiar influences on the UK, they are potentially useful to see how collaborative networks have evolved over time, given extensive UK links with researchers in other English-speaking countries and in other European countries. Articles from the end of WWII in 1946-2018 are studied, as this period encompasses potential changes associated with the Cold War, resource interests and more recent environmental interests. The databases used here in combination can address this period, though are incomplete prior to then.

Bibliometric analyses have been carried out on Earth and environmental fields before (Bjurström and Polk 2011; Jappe 2007; Liao and Huang 2014; Liu et al. 2012; Rey-Rocha and Martín-Sempere 2004; Wagner and Leydesdorff 2003; Wang et al. 2010, 2013; Zhou et al. 2007; Zhuang et al. 2013), and some on sub-areas of marine science (Aksnes and Browman 2016; Chiu and Ho 2007; Dastidar 2004; Zhang et al. 2009). However, none as far as the author is aware has been carried out on the whole of Oceanography or Marine Geoscience as defined above.

There are unfortunately no subject classifications that perfectly encompass the whole of either Oceanography or Marine Geoscience, making the searching for articles 
difficult. There are differences in the titles covered by Web of Science (WoS) and Scopus (Bosman et al. 2006; Burnham 2006). The Oceanography categories in both databases do not cover all the output of Oceanography entirely, e.g., the WoS Oceanography category omits marine fisheries. There is a separate Fisheries category in WoS but it includes freshwater fisheries as well as marine fisheries. The Marine Geology category of Georef includes some oceanographic articles and their proportion of the category was found here to have varied with time. The WoS and Scopus category searches did not return articles published in the high-impact journals Nature, Science or the Proceedings of the National Academy of Sciences, since these journal articles are assigned to other categories. Given these problems, searches were developed only to capture the bulk of each field. If the high-impact journal articles form a constant proportion of the field's articles or if that proportion is small relative to the field as a whole, their omission should not greatly affect the trends found. The intention was thus to derive time series of these fields sufficiently well to reveal major inflections and to quantify their exponential rates of growth or decline. These can be compared against other data relevant to the amount of activity in these fields represented by data and sample collection at sea, as well as historical developments.

\section{Publication databases used}

The Web of Science ${ }^{\mathrm{TM}}$ Core Collection is a large database of publications originally developed by the Institute of Scientific Information and now owned and operated by Clarivate Analytics (https://clarivate.com/). Clarivate Analytics states that the database presently covers $>20,000$ journals and contains publications from the year 1900 onwards. Articles within WoS have been assigned the relevant classes "Oceanography", "Marine and Freshwater Biology" and "Fisheries".

Scopus (https://www.scopus.com/) is a database that, as of 2018 , contained $>71$ million records covering $>23,700$ journal titles, encompassing all the sciences and engineering. Classes used in the database include "Oceanography", "Aquatic science", "Ocean Engineering" and "Water Science and Technology".

Georef is a specialist publications database produced by the American Geosciences Institute focused on the geosciences. It is more extensive in the geosciences than WoS and Scopus, including reports and other publications. Many marine geoscience articles published in more generalist journals such as Journal of Geophysical Research are included.

\section{Methods}

\section{Searches of bibliographic databases}

The text here describes how the searches were carried out, whereas a later section evaluates which of these searches are the most effective in capturing publication trends in oceanography. The terms used in the searches described below are provided in the electronic supplement to this article. Searches were carried in July 2019 of articles published up to and including 2018. 


\section{Web of Science}

An initial search was carried out for articles using the subject category "Oceanography" (black symbols in Fig. 1). Two further categories "Marine and Freshwater Biology" and "Fisheries" are provided within WoS. As marine biology and fisheries are a major part of the marine sciences, a further search was carried out using these two terms as well as "Oceanography". These categories contain articles on freshwater research, so it was necessary to exclude some source names reflecting predominantly freshwater research to reduce their influence on the results. Address fields are only occasionally filled in the earlier years so these search results are only useful to study the UK articles from 1973 onwards.

Jarić et al. (2012) developed a bibliometric study of fisheries based on specialist journal names. As oceanographic research is also well identified by the names of a large number of specialist journals, a further search for publications was carried out using "Journal of Marine *", "Marine *" and "Ocean*", and 47 other individually named journals. Excluding journals dominated by freshwater articles as before led to the results shown by the blue symbols in Fig. 1 .

To investigate collaborations of researchers in the UK and other countries, the results obtained using the WoS Oceanography category search were refined using the names of each of the top 12 collaborating countries by total record counts. Their annual counts are shown in Fig. 2 as proportions of the UK total output after a 5-year running average was applied to reduce variability.

The 2009-2018 (10-year) average number of UK publications with co-authors in each country was calculated and is shown in Fig. 3 as a ratio to the number of UK publications with USA-based co-authors. The ratio of the general population sizes of those countries is also shown in the figure (open symbols).

The lengths of author lists shown in Fig. 4 were extracted from the WoS UK Oceanography category search results for convenience (larger downloads of detailed records are possible than with Scopus). The proportion of publications with one or two authors are shown as a proportion of all publications in Fig. 4a and their absolute numbers are shown in Fig. 4b. In Fig. 4c, those data are shown with a logarithmic vertical axis to reveal if the trends are exponential.

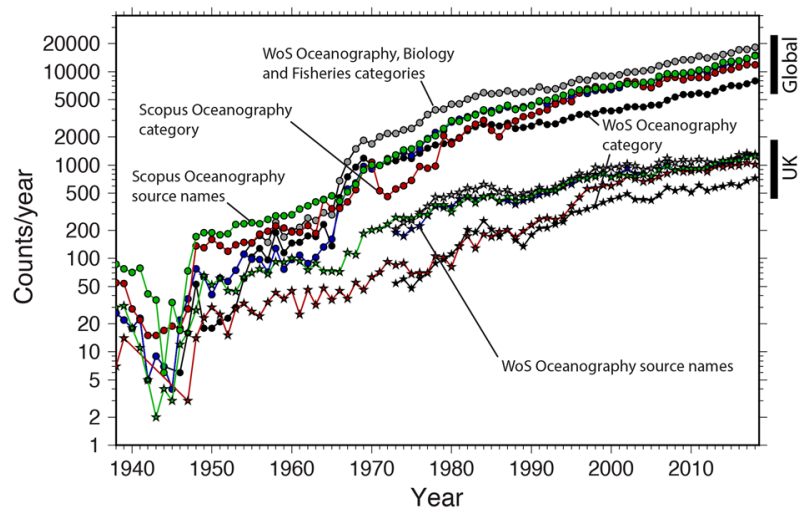

Fig. 1 Various measures of global (circles) and UK (star symbols) article publication rates for Oceanography. Curves derived from Web of Science ${ }^{\mathrm{TM}}(\mathrm{WoS})$ are shown for searches using (black symbols) the Oceanography category, (grey) the Oceanography, Biology and Fisheries categories combined and (blue) source names. Curves derived from Scopus ${ }^{\mathrm{TM}}$ are shown for searches using (red) the Oceanography category and (green) source names. (Color figure online) 


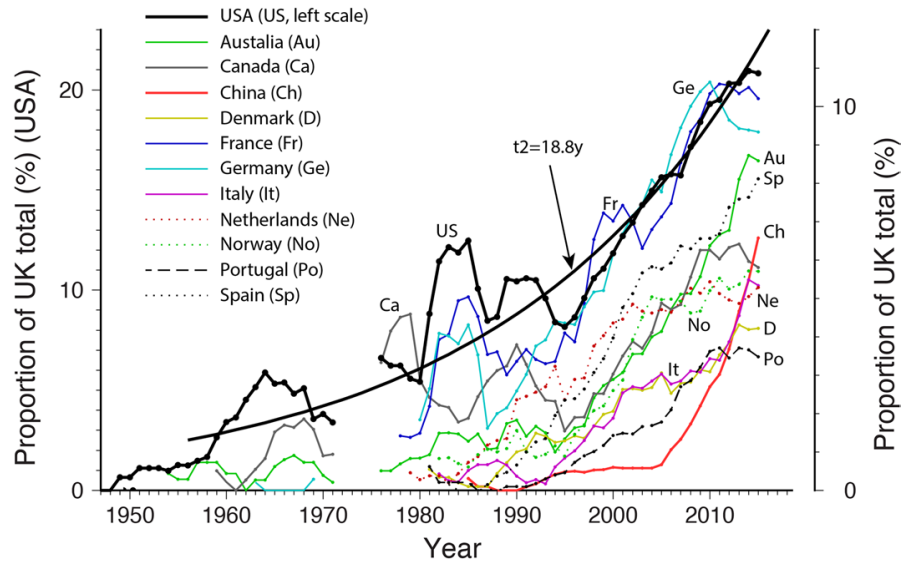

Fig. 2 Coauthored Oceanography articles in Fig. 5a as percentages of UK total Oceanography articles derived from (post-1973) the Web of Science Oceanography category search and (pre-1973) the Scopus source names search. A 5-year running average has been applied to reduce variability. Smooth curved line is an exponential trend fitted to the USA data

Fig. 3 Numbers of UK collaborative articles with coauthors from the countries shown given as a ratio to those with USA-based coauthors, derived from the Web of Science Oceanography category search (averages over 2009-2018). Population ratios (open circles) were derived from entries in Wikipedia. (Color figure online)

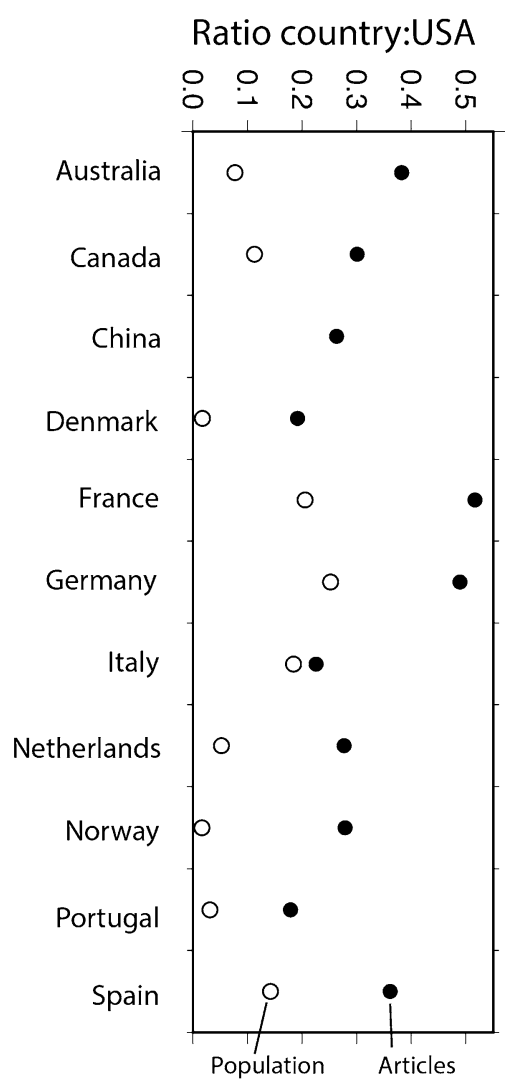


Fig. 4 Author numbers derived from the Web of Science Oceanography category search results for UK-authored articles. a The proportion of articles with one or two authors only (circles and crosses, left-hand scale), the mean and median average number of authors (first right-hand scale) and maximum number of authors (second righthand scale). b Numbers of UK single and double author articles in Oceanography corresponding with the proportions in (a). c Mean, median and maximum numbers of authors from (a) with a logarithmic vertical axis. Dashed lines are regressions of the mean and maximum author numbers from 1973 to 2018
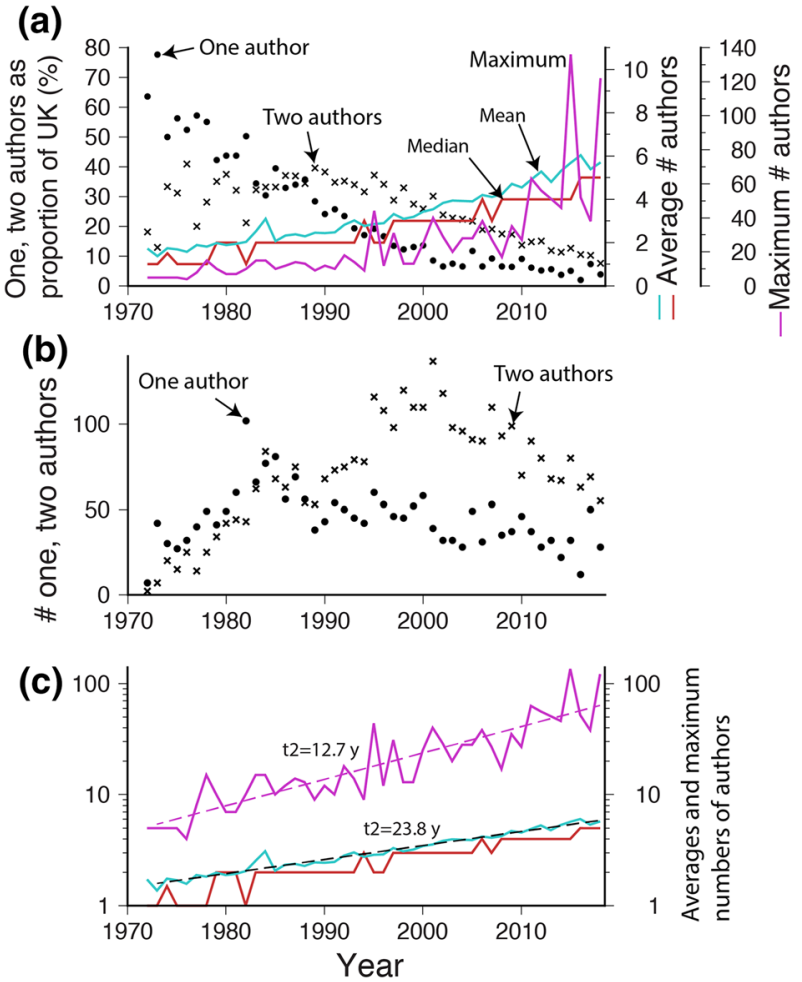

\section{Scopus}

Initially, a search was carried out using the subject category "Oceanography". The results are shown with the red symbols in Fig. 1. A second Oceanography search was attempted using source names as for the second Web of Science search. These results were also used to isolate the collaborative articles in the pre-1973 period for Fig. 2, where author countries are incompletely recorded in WoS.

\section{Georef}

A search was carried out using the subject classifications "Marine geology and oceanography" and "Geophysics-solid Earth" (Georef category numbers 07 and 18), with the results for "Geophysics-solid Earth" conditioned using five Controlled Vocabulary terms to reduce the identification of non-marine articles (Electronic supplement). The Georef category "Marine geology and oceanography" includes work on "continental shelf, continental slope, ocean floors, ocean waves (sediment transport), ocean circulation (sediment transport), reefs (modern)" according to the American Geosciences Institute (www.americangeosciences.org). However, this was found to exclude much solid-earth geophysics and related modelling carried out in the oceans to determine geological structure so it was considered inadequate for the purpose here. Hence the 
Geophysics category was also used. A classification term "Estuarine" was also used to capture much of coastal geoscientific work, which is often carried out in estuaries.

This search for "Journal articles" also returns many short conference abstracts that are clearly not peer-reviewed journal articles. Using source title names for the major conferences of the American Geophysical Union and other organizations, these abstracts were removed from the results, reducing the total count by $20 \%$. These reduced search

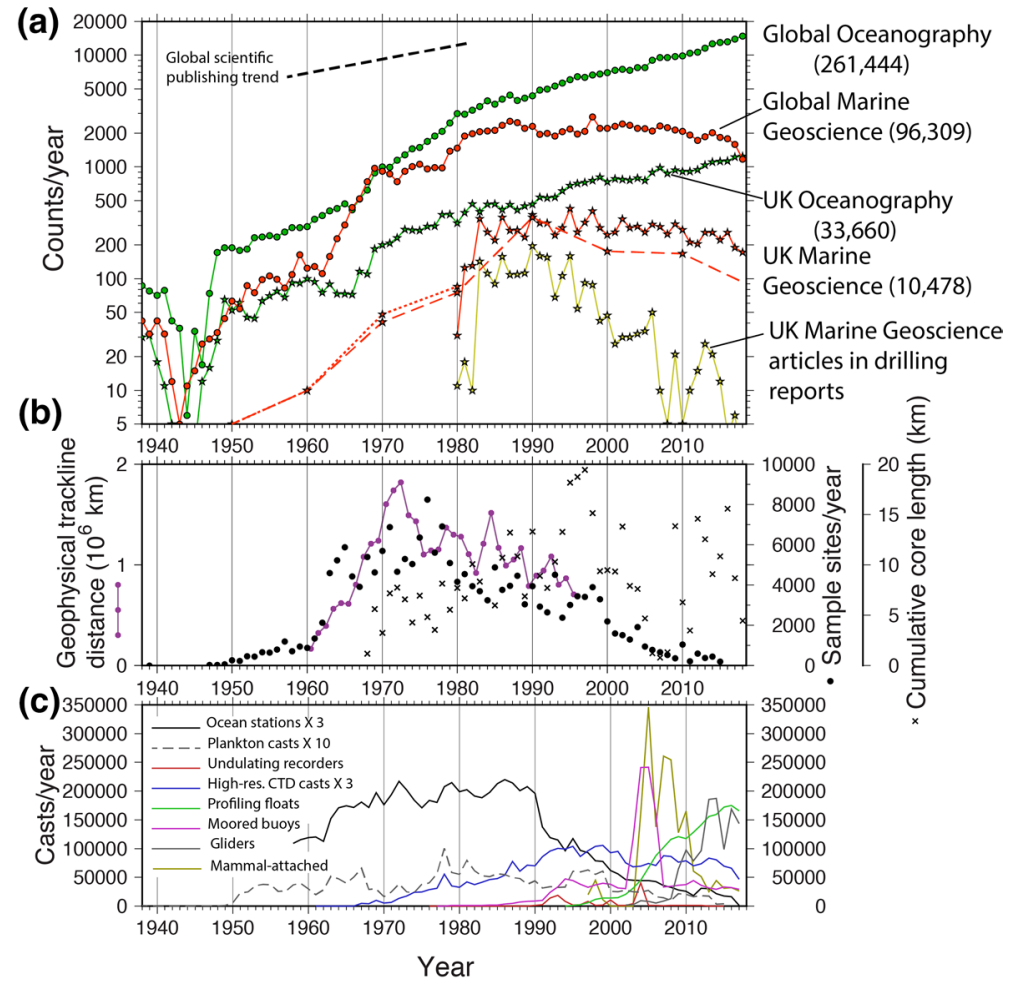

Fig. 5 a Publishing rates in Oceanography (green symbols) derived using source titles in Scopus ${ }^{\mathrm{TM}}$ (Fig. 1). Curves in red show articles derived using the marine geoscience and oceanography category in Georef ${ }^{\mathrm{TM}}$. Dotted red lines connect UK publications within the Georef global results each decade 1940-1980. Dashed red lines show decadal UK Marine Geoscience articles classified by the author from the Georef UK results. Symbols connected by yellow lines are articles within the UK Georef search results that are in reports of the Deep-Sea Drilling Project (DSDP), Ocean Drilling Program (ODP) and Integrated Ocean Drilling Program/International Ocean Discovery Program (IODP). Note vertical scale is logarithmic, so exponential increases appear as straight lines. Bold dashed line represents the graph-gradient expected for the global exponential rate of scientific publishing from Bornmann and Mutz (2015). Values in brackets on right are total article numbers found in each search. b Data in feint magenta are track-line distances of all marine geophysical data archived at the National Centers for Environmental Information by 2010 excluding data after 1995 affected by archiving delays (Wessel and Chandler 2011). Solid circles are annual numbers of seabed samples using data obtained from GeoMapApp (www.geomapapp.org) originating from 23 sample archive facilities. X-symbols represent annual total lengths of core samples obtained by the DSDP and ODP (http://www.odplegacy.org/samples_data/data.html) and from the IODP (www.iodp.org). c Rates of collection of ocean casts by various methods obtained from the World Ocean Database 2018 (Boyer et al. 2018). Within the key, "Ocean stations" represent ocean station data (low resolution casts taken from ships), "CTD" represents high-resolution conductivity-temperature-depth and "Mammal attached" are autonomous pinniped bathythermograph data 
Fig. 6 Proportion of marine geoscience articles with co-authors from the countries shown, derived from the Georef Marine Geology and Oceanography category search. A 5-year running average has been applied to reduce variability

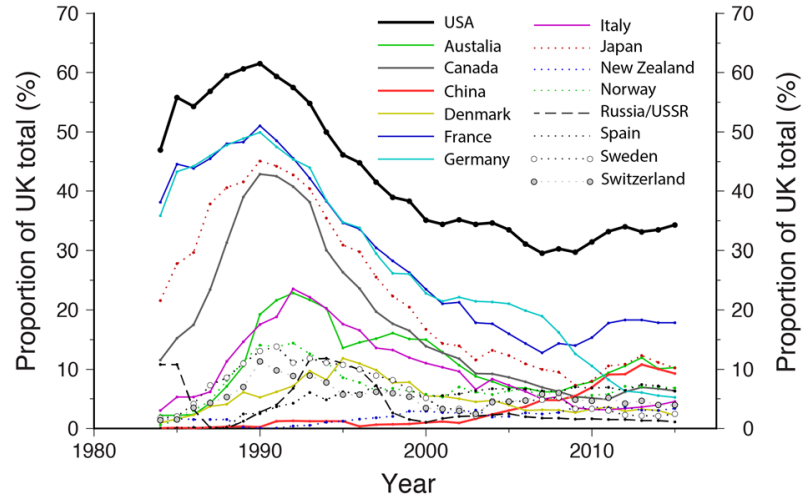

Fig. 7 Author numbers for articles derived from the Georef category search, as Fig. 4 (note slightly different vertical scales). Small circles on curve of maximum numbers of authors indicate where articles related to the scientific drilling programmes DSDP, ODP and IODP (a)
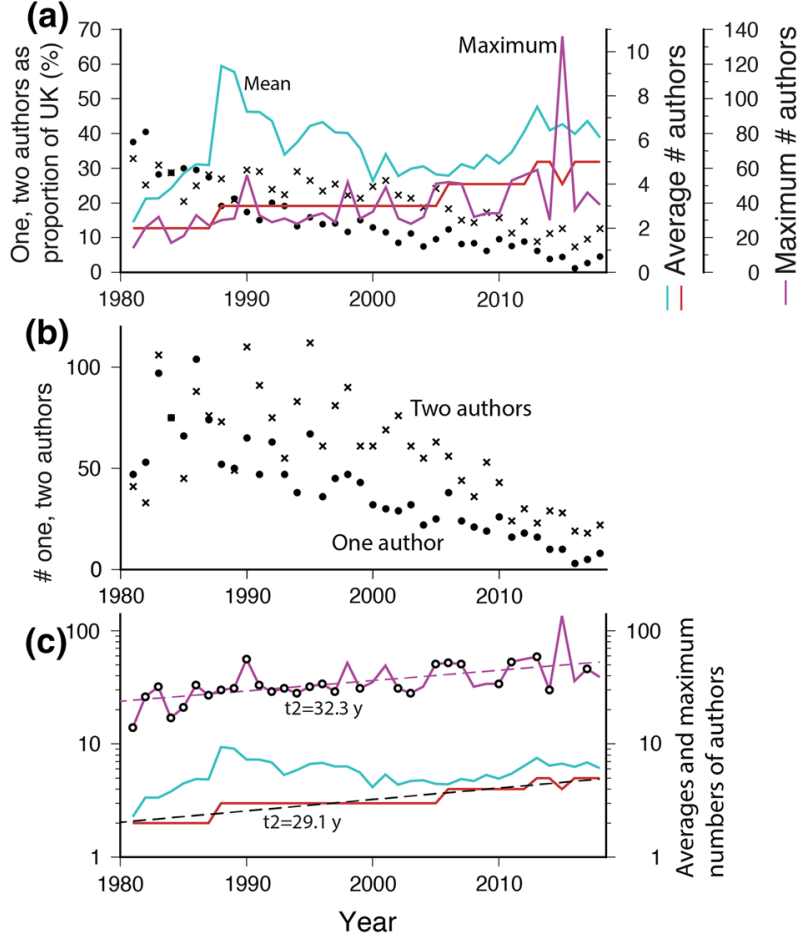

results were used to derive the global and UK publishing rates joined by continuous lines in Fig. 5, collaborative article proportions in Fig. 6 and author numbers in Fig. 7.

To assess accuracy of the AGI classifications, the author classified the search results at decadal intervals into purely Marine Geoscience, Oceanography (articles concerning only water column processes or properties) and Terrestrial (articles concerning geology on land, including ancient marine geology, or deeper mantle processes or structures). The results are shown by the red dashed line in Fig. 5a. Annual counts of the drilling reports with UK authors are also shown in Fig. 5a. Their decline with time reflects a general change in dissemination to reporting in the mainstream literature (Wang et al. 2016). 


\section{Measures of data and sample collection intensity}

For comparison with the publication rates, Fig. 5b shows measures of marine geophysical data and sample collection rates. The geophysical track-line distances in Fig. 5a represent annual total research vessel travel distances calculated from geophysical data archived at the National Centers for Environmental Information (www.ncei.noaa.org) by Wessel and Chandler (2011). Even expeditions that were not primarily geophysical, such as focused on seabed sampling, often involved collecting echo-soundings and ship positions between sites, so this is a useful broad measure of ship time.

The number of sampling sites per year was obtained from core, grab and rock dredge sites listed in 23 sample archives within the GeoMapApp data browser (www.geoma p.org; Electronic supplement). These include 19 in the USA, as well as national facilities in Canada, Germany and the UK. This omits some important archives from countries such as France, and likely some sampling in shallow coastal waters where archiving is less common. The data potentially also suffer from delays in recording samples similar to those affecting the geophysical track-line data after 1995 (Wessel and Chandler 2011), possibly explaining the decline in sampling rates after the year 2000. Nevertheless, these data cover a large part of sample collection in deep waters by the developed countries and present a broad measure of geological marine field activity. Total cored sediment and rock obtained by the Deep Sea Drilling Project, Ocean Drilling Program, Integrated Ocean Drilling Program and International Ocean Discovery Program shown in Fig. 5b were calculated after assigning a year to each expedition of the drilling vessels (core length data and dates are from (http://www.odplegacy.org/samples_data/ data.html and www.iodp.org).

The intensity of oceanographic data collection at sea is more difficult to characterize given the diversity of activities involved, but temperature and salinity are basic measurements commonly made. Figure $5 \mathrm{c}$ shows a selection of the more important measurements archived within the World Ocean Database 2018 of the National Oceanographic and Atmospheric Administration (Boyer et al. 2018). The data are shown separated by method of measurement. Note that only the plankton casts represent biological assessments and the database omits measures of current velocity and acoustical and optical oceanography.

\section{Data characterizations}

Exponential trends were characterized by resolving the exponential parameter $k$ :

$$
Y=Y_{0} \exp (k t)
$$

where $Y$ is either publication rate (articles/year) or numbers of authors, $t$ is calendar year and $k$ and $Y_{0}$ are constants. The doubling time $t 2$ quoted below equals $\ln 2 / k$. These values were found in practice by fitting straight lines to $\log (Y)$ by least squares regression (Wessel and Smith 1991).

For assessing the association between pairs of data series $X_{i}$ and $Y_{i}$, the following simple correlation coefficient (Miller and Freund 1965) was computed:

$$
R=\frac{S_{x y}}{\sqrt{S_{x x} S_{y y}}}
$$


Table 1 Doubling times ( $t 2)$ derived using Eq. (1)

\begin{tabular}{ll}
\hline Year range $^{\mathrm{a}}$ & $t 2$ (years) \\
\hline Global oceanography articles from scopus & 6.5 \\
$1969-1980$ & 17.0 \\
1980-2018 & 2.3 \\
Global Marine Geoscience articles from georef & \\
1962-1969 & 11.7 \\
UK oceanography articles from scopus & 21.9 \\
1969-1980 & \\
1980-2018 & 7.3 \\
UK marine geoscience from georef: & $16.2^{\mathrm{b}}$ \\
1950-1980 & 18.8 \\
1990-2018 & \\
UK-USA collaborative articles as \% of all UK oceanography in scopus & 23.8 (means) \\
1956-2018 & 12.7 (maxima) \\
Author numbers of UK oceanography articles from WoS oceanography & 29.1 (median) \\
1973-2018 & 32.3 (maxima) \\
1973-2018 & \\
Author numbers of UK marine geoscience articles from georef & \\
1981-2018 & \\
1981-2018 & \\
\hline
\end{tabular}

${ }^{\mathrm{a}}$ All years shown inclusive

${ }^{b}$ Half-life of declining publications derived from this author's classification of the UK Marine Geoscience search results from Georef

Table 2 Associations investigated using Eq. (2)

\begin{tabular}{|c|c|c|c|c|}
\hline Parameter $1\left(X_{i}\right)$ & Parameter $2\left(Y_{i}\right)$ & Year range $^{\mathrm{a}}$ & $R$ & $R$ (filtered data ${ }^{\mathrm{b}}$ ) \\
\hline Global $\mathrm{MG}^{\mathrm{c}}$ article rates & Geophysical track-line km & 1960-1972 & 0.92 & 0.87 \\
\hline Global $\mathrm{MG}^{\mathrm{c}}$ article rates & Geophysical track-line km & $1972-1995$ & -0.62 & -0.70 \\
\hline Global $\mathrm{MG}^{\mathrm{c}}$ article rates & Seabed sampling sites & $1960-1972$ & 0.64 & 0.84 \\
\hline Global $\mathrm{MG}^{\mathrm{c}}$ article rates & Seabed sampling sites & $1972-1995$ & -0.70 & -0.76 \\
\hline Global $\mathrm{MG}^{\mathrm{c}}$ article rates & Drilling core lengths & $1968-2018$ & 0.57 & 0.40 \\
\hline Global Oceanography ${ }^{\mathrm{d}}$ article rates & Ocean Station + CTDs & $1960-1970$ & 0.72 & \\
\hline Global Oceanography ${ }^{\mathrm{d}}$ article rates & Ocean Station + CTDs & 1971-1990 & 0.82 & \\
\hline Global Oceanography ${ }^{\mathrm{d}}$ article rates & Ocean Station + CTDs & $1991-2017$ & -0.84 & \\
\hline Geophysical track-line km & Seabed sampling sites & $1960-1995$ & 0.56 & \\
\hline Geophysical track-line km & Drilling core lengths & $1968-1995$ & -0.52 & \\
\hline UK Oceanography article rates & UK funding (NERC) $)^{\mathrm{e}}$ & 1985-1997 & 0.64 & \\
\hline
\end{tabular}

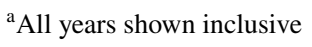

${ }^{b}$ After the measures of data collection at sea were filtered by averaging every 4 years and applying that average to the 4 th year (Eq. (3))

${ }^{\mathrm{c}}$ Marine Geoscience article publication rates obtained from Georef

${ }^{\mathrm{d}}$ Oceanography publication rates obtained from Scopus

eNERC science budget and commissioned research in marine science according to the Parliamentary Office of Science and Technology (1999) 
where $S_{x y}$ is the sample covariance and $S_{x x}$ and $S_{y y}$ are the sample variances of $X_{i}$ and $Y_{i}$. The results of applying Eqs. (1) and (2) to data are summarized in Tables 1 and 2.

In practice, a researcher acquiring geophysical data or samples at sea takes some time to analyze them before publishing. Article peer review could take at least 6 months in the years before electronic publishing. Also as the data series are noisy, it is appropriate to filter them and apply a delay before comparing them with the article rates. To represent this, the geophysical and sample data series were filtered with a 4-year simple running average and that average applied to year 4 of the filter (effectively representing an average 2-year delay from data or sample collection to publication):

$$
Y_{i, \text { filtered }}=\left(Y_{i-3}+Y_{i-2}+Y_{i-1}+Y_{i}\right) / 4
$$

where $Y_{i}$ are the numbers of sample stations, core lengths or geophysical track-line lengths.

\section{Evaluation of bibliographic search results}

Before interpreting the publication rates, differences between the search results derived from the different bibliographic databases and their general effectiveness in representing the subject areas need to be considered. The different global search results in Fig. 1 have similar graph gradients after 1995 so they have similar exponential growth rates and doubling times in the more recent past despite differences in magnitude. However, the Oceanography category search results deviate in ways that suggest non-uniformity in article classifications in both Scopus and WoS from the 1950s to 1980. For the year 1950, for example, the WoS search recovered only articles in the Journal of Marine Systems, whereas the Scopus search recovered articles from seven different journals, partly reflecting a general bias in WoS towards English-language journals (van Leeuwen et al. 2001). The search using the WoS Fisheries and Biological categories captures more articles than the other searches from 1970 onwards, though it falls below the Scopus Oceanography search results in the 1950s. The extent to which search results remained contaminated by freshwater research is also uncertain.

The Scopus search results using Oceanography source names are generally smoother than the other searches for the period 1948-2018. The WoS search results almost coincide with them from the late 1960s onwards, though with short-lived deviations below them. However, they lie below the Scopus search before the late 1960s, because of the journals missing from the WoS database. The WoS records do not contain UK country codes prior to 1973. Overall, the search using Scopus Oceanography source names appears to be the most effective in capturing the exponential rates and changes of trend so it is preferred here as a measure of Oceanography publishing. These search results are reproduced in Fig. 5 for comparison with the Georef search results and other data.

The classification by the author of the UK Marine Geoscience articles revealed that the Georef search results were accurate for the period 1950-1990 (Fig. 5a, comparing red dashed and dotted lines). However, an average $44 \%$ articles were from outside Marine Geoscience for 2000, 2010 and 2018, due in part to inclusion of oceanography articles by the American Geoscience Institute in their Marine Geology and Oceanography category. Browsing the Global Marine Geoscience search results suggests that they are similarly affected. No correction has been made for this non-constant classification in the global results, but the discussion of the post-1990 decline in rates below bears in mind this contamination. 


\section{Observations}

\section{Global publishing trends}

The Scopus Oceanography results in Fig. 5a show a general rise in publication rates over time after WWII in three stages: $1948-1967(t 2=12.1 \mathrm{y}), 1969-1980(t 2=6.5 \mathrm{y})$ and $1980-2018(t 2=17.0 \mathrm{y})$.

Global Marine Geoscience publishing rates in Fig. 5a also participated in the rapid expansion after WWII. For a short 8-year period (1962-1969) the doubling time was only 2.3 years. Publication rates continued to increase into the mid-1980s, after which they declined.

\section{UK publishing trends}

The Scopus Oceanography search results for the UK show a general increase since WWII besides a dip below trend by about a factor of two in the mid-1960s and a smaller dip in the late 1980s. The graph gradient for UK Oceanography in the 1970s is shallower than global Oceanography (1969-1980: $t 2=11.7$ y compared with $t 2=6.5 y$ globally). During the 1950 s, UK authors published $28 \%$ of global publishing on average, but that proportion declined over time and during 2018 it was $8 \%$. Consequently, the doubling time has been longer more recently $(1980-2018: t 2=21.9 y)$ than for global Oceanography $(1980-2018$ : $t 2=17.0 \mathrm{y})$.

The UK Marine Geoscience publishing rate also increased following WWII. For $1950-1980, t 2=7.3 y$. Subsequently, largely due to articles associated with scientific drilling, publishing rates abruptly increased from $4.9 \%$ on average $1960-1980$ to $13.2 \%$ of Global Marine Geoscience in 1990 (values from Georef results not adjusted from nonmarine or oceanography articles for consistency). After 1990, publication rates declined, though remained high proportions of Global Marine Geoscience (11.6\% average for 2000-2018). From the manually classified UK articles for 1990-2018, publishing rates have been decreasing with a half-life of $16 \mathrm{y}$.

\section{Collaborative articles}

Collaborative articles in Oceanography have generally increased as a share of UK publishing over time, although the curves differ in form among countries (Fig. 2). The share of publishing with USA-based researchers increased from the 1950 s onwards $(t 2=18.8 \mathrm{y})$. Strong increases can be observed with researchers in the other English-speaking countries Australia and Canada, the former tending to lag behind the latter. Increases are observed also with European countries. Collaborative publications involving co-authors in China have been increasing from the early 1990s, most abruptly from the mid-2000s. The data in Fig. 2 were filtered with a 5-year running average to reduce variability and make the trends easier to see, though the filtering spreads out the trend for the China collaborations. Without that filtering, those collaborative articles doubled as a percentage of UK Oceanography articles from 2014 to 2018.

Figure 3 highlights the strengths of those collaborations relative to the populations of the countries involved. Differences between the population and article ratios reveal that collaborations were particularly strong between the UK and most of the countries shown except for Italy, for which the ratios are nearly aligned. Furthermore, the China:USA population ratio 
(4.25) lying off the graph is still greatly above the article ratio despite the rise in UK-Chinese collaborations.

Data for marine geosciences (Fig. 6) have a different pattern from the mid-1980s onwards, when author affiliations were recorded in Georef. Collaborative articles as shares of UK publications mostly peaked in 1990 for the USA, France, Germany and Japan and somewhat later for most other countries. Since then, most of the collaborative percentages declined towards the present, though collaborations with American, French and Japanese scientists have increased modestly from $\sim 2008$. Collaborative articles with Chinese researchers, in contrast, only began increasing from around 2000 and formed only 10\% of UK Marine Geoscience publications by 2018 .

\section{Numbers of authors per article}

In the WoS search results for UK Oceanography (Fig. 4), the mean author length was only $\sim 2$ in the mid-1970s and median average was only 1 for some years. From there, the mean increased to nearly 6 by 2018 whereas the median increased to 5 (mean $t 2=23.8 \mathrm{y}$ ). In contrast, the maxima increased more dramatically $(2=12.7 \mathrm{y})$. A faster rise of the top end of the distribution of author lengths, making the distribution progressively broader, explains why the median author length has not risen quite as much as the mean.

In tandem, the proportion of articles with only one or two authors has declined. Singleauthor articles, which comprised $78 \%$ of the UK total Oceanography output in 1973, decreased to below $4 \%$ by 2018 . While this change is partly a result of dividing by the increasing UK total Oceanography counts (Fig. 5a), the absolute numbers of single author articles peaked at 102/year in 1982 and subsequently declined to only 28/year in 2018 (Fig. 4b). Articles with two authors reached 137/year in 2001 and then decreased to 55/year by 2018.

In the UK Marine Geoscience search results (Fig. 7), the mean author length peaked in 1988 at 9, subsequently declined into the 2000s before increasing again. This contrasts with the median average and the maxima, which increased more progressively, with 29.1 and 32.3 year doubling times, respectively. The number of single author publications peaked at 104/year in 1986 before declining to only 8/year in 2018. The number of publications with two authors peaked at 112/year in 1995 before declining to 22/year in 2018.

The Marine Geoscience mean and maximum author lengths are strongly affected by many articles arising from the international scientific drilling programmes [Deep Sea Drilling Project (DSDP), Ocean Drilling Program (ODP) and International Ocean Drilling/Discovery Program (IODP)], as reports of those programmes after the 1970s typically involved the entire scientific party of each expedition. Where maxima involve results of these programmes, they are highlighted in Fig. 7c. The drilling ships used in these programmes steadily increased their numbers of berths for seagoing scientists over time. Drilling research vessel (DRV) Glomar Challenger operated before 1983, with reports appearing until 1987, whereas DRV JOIDES Resolution began operating from 1985, with a major refit during 2007-2008.

\section{Discussion}

\section{Fundamental changes in style of marine science research}

Up to 1972, global publishing rates in Marine Geoscience were positively correlated with geophysical track-line distances (1960-1972: $R=0.92)$. Subsequently, the correlation was 
negative (1972-1995: $R=-0.62)$. It is interesting to look at the track-line distance per article published in this subject area. Over 1960-1972, that ratio was consistently high, averaging $2210 \mathrm{~km} /$ article, reaching $3561 \mathrm{~km} /$ article in 1963, but it subsequently declined, reaching only $323 \mathrm{~km} /$ article in 1995 . For context, a research vessel underway at 10 knots traverses $444 \mathrm{~km}$ in $24 \mathrm{~h}$ and a deep-water research cruise takes typically a month. The seabed sampling rates also increased rapidly in the early 1960s, show little systematic variation with time in the mid-1960s to late 1970s and subsequently declined into the 1990s and 2000s. Although noisier than the track-line distances, they also show a change from positive to negative correlation with publication rates at the start of the 1970s (1960-1972: $R=0.64 ; 1972-1995: R=-0.70)$. In the period $1960-1972$, there were on average 8.9 seabed samples per article published. That ratio remained high through 1972-1978 (on average 6.3 samples per article) but then declined to on average 1.9 samples per article through 1979-1995. The cumulative annual lengths of core recovered by the drilling programmes modestly correlate with publication rates $(1968-2018: R=0.57)$. There were on average $3.9 \mathrm{~m}$ of core recovered per article published in Marine Geoscience generally with no systematic variation with time over 1968-2018. However, this does not account for the article counts being somewhat over-estimated towards the end of that period as explained earlier. The $R$-values derived after filtering to allow for the finite time needed to analyze and publish results using Eq. (3) suggest stronger correlations (hence modestly supporting the suggested delays between field activities and publication) except for the drilling sample lengths (Table 2).

The change in 1972 of publication rates from positively correlating with track-line distances and seabed samples to negatively correlating suggests a major change occurred in the way marine geoscientific research was carried out. There are several possible explanations. The seafloor spreading interpretation of marine magnetic anomalies (Vine and Matthews 1963) and plate tectonic theory (McKenzie and Parker 1967) ultimately led to reinterpretation of magnetic and other geophysical data that had been collected previously, e.g., Fisher and Sclater (1983). Other kinds of model-based analysis of data emerged which did not require collecting new data at sea (e.g., Parsons and Sclater 1977). Analysis of paleoceanographic signals in sediments (Arrhenius 1963; Emiliani 1955) became increasingly popular and took advantage of cores collected in earlier years (Bond 1999).

There were also major improvements in technology, which allowed more information to be collected during each cruise. The DSDP began in 1968 (Ewing 1969). Core samples, underway geophysics and downhole geophysical logs acquired during the DSDP and subsequent ODP represent a major jump in the rate of information acquired. Hydraulic piston coring (Prell and Gardner 1982) led to the recovery of undisturbed sediment samples and enabled a greater range of paleoceanographic analysis (Theyer et al. 1989). The greater efficiency of piston coring compared with the earlier rotary drilling in unlithified sediments is partly responsible for the cumulative core lengths in Fig. 5b increasing from average $5386 \mathrm{~m} /$ year in 1968-1979 to $9485 \mathrm{~m} /$ year in 1980-2018. Other drilling vessels and platforms were also introduced within the IODP (www.iodp.org). Geophysical equipment became more sophisticated and widely available, including the Scripps Deep-Tow from the 1970s (Spiess and Lonsdale 1982; Spiess and Tyce 1973), multibeam echo-sounders from the late 1970s (Farr 1980; Renard and Allenou 1979), and long- and short-range sidescan sonar from the 1960s (Rusby et al. 1969; Stubbs 1963). Simple correlation coefficients calculated using Eq. (2) between the geophysical track-line distances and the other data support this (Table 2). While the seabed sample sites are correlated with track-line distances (1960-1995: $R=0.56)$, the core distances are inversely correlated (1960-1995: $R=-0.52)$, so scientific drilling, to some extent, displaced research using geophysical equipment and 
shallow sampling. Geophysical data (seismic reflection, sediment profiler and bathymetry data) are needed prior to drilling sites for safety reasons and because structures revealed by them help scientists pose the problems in proposals that are addressed by drilling. In the period 1968-1979, there were $328 \mathrm{~km}$ of geophysical track-line data collected per metre of core collected by scientific drilling, but for 1980-1995 only $109 \mathrm{~km}$ per metre of core were collected.

To compare with the Oceanography article counts, the annual casts of Ocean Station Data and higher resolution CTDs (Fig. 5c) were summed together because they both represent dominantly ship-based data or sample collection. That sum correlates with article counts through the 1960s $(1960-1970: R=0.72)$ and through the 1970s and 1980s (1971-1990: $R=0.82$ ). Subsequently, the correlation became negative (1991-2017: $R=-0.84$ ). Figure 5 c illustrates how collecting data changed in $\sim 1990$ to methods using less vessel time for a given amount of ocean temperature, salinity and other information, such as by using autonomous profiling floats, moored buoys, gliders and mammals. The logarithmic Oceanography article counts changed gradient in the 1980s at about this time, so this change did not cause productivity to accelerate, rather the exponential rate decreased and doubling time increased. Also contributing to a change though less quantifiable, satellite-based remote-sensing has become important in oceanography at least since the launches of SEASAT and Nimbus-7 in the 1970s (Gower 2010). The part of oceanography effort involving modelling is also difficult to quantify, though Zhang et al. (2009) found that articles on ocean circulation, for which modelling is important, increased as a power function of year from 1994 [rate proportional to (year-1994) ${ }^{1.62}$ ]. Jarić et al. (2012) found a change in fisheries research in which modelling and discussion in articles increased from 2000-2004 to 2005-2009, while field study and data assessment declined.

\section{Prices of commodities and global oceanography and marine geoscience research}

Relationships between publication rates and global commodity prices suggest complex motivations. For example, global inflation-adjusted food and beverage prices (Spatafora and Tytell 2009) shown in Fig. 8, which were highest in the mid-1970s and declined gradually to a minimum in 1999, do not correlate with Oceanography publishing trends in Fig. 5a. The decline in exponential rate of publishing growth coincides with an abrupt decline in the prices in the mid-1980s, so there is arguably some connection between them. The breakdown in Fig. 9a also shows many western institutions had flat or, in some cases, reduced publication rates in the late 1980s. Nevertheless, the general lack of correlation with prices suggests that decisions on supporting oceanographic research financially also involve other considerations, such as employment, security of food supply and the environment.

A high price of crude oil may encourage governments to invest more in Marine Geoscience if they perceive that it supports their domestic offshore oil and gas industries. It may also benefit some aspects of oceanographic research associated with offshore oil and gas, such as physical oceanography, weather forecasting and environmental research. The negative economic impacts of high prices of imported crude oil and gas may encourage research and development in offshore wind, tidal and wave power. On the other hand, a high price of marine fuel makes research vessel usage more expensive and, if budgets are limited, could reduce funding to other areas of research activity. Concerning vessel costs, Wessel and Chandler (2011) noted a general lack of association of geophysical track-line 


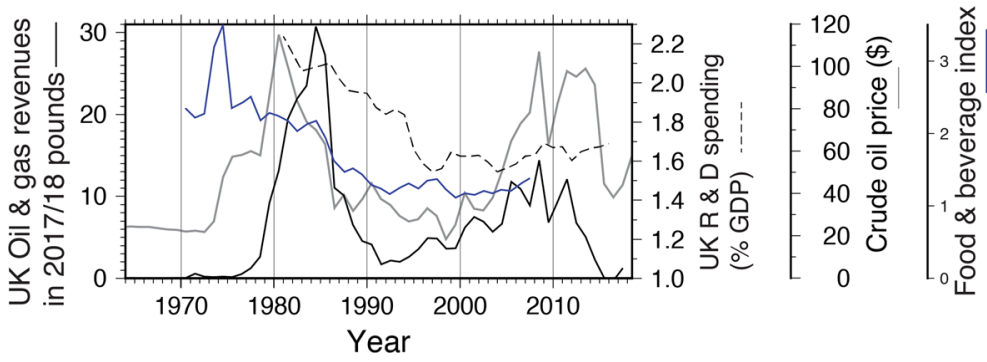

Fig. 8 Dashed line is UK gross expenditure on research and development (OECD 2018). Solid black line represents UK government oil and gas revenues adjusted for inflation (/www.ogauthority.co.uk, accessed 02/07/2019). Grey line is Illinois Sweet Crude adjusted for inflation to 2019 prices (inflationdata.com). Blue line is a composite index of food and beverage prices adjusted for inflation (Spatafora and Tytell 2009)

Fig. 9 Publication rates by author affiliation for global a Oceanography and b Marine Geoscience articles (i.e., corresponding with the results in Fig. 5a). Data are shown for the top publishing organizations by total article count and have been smoothed with a 5-year running average filter (a) Oceanography

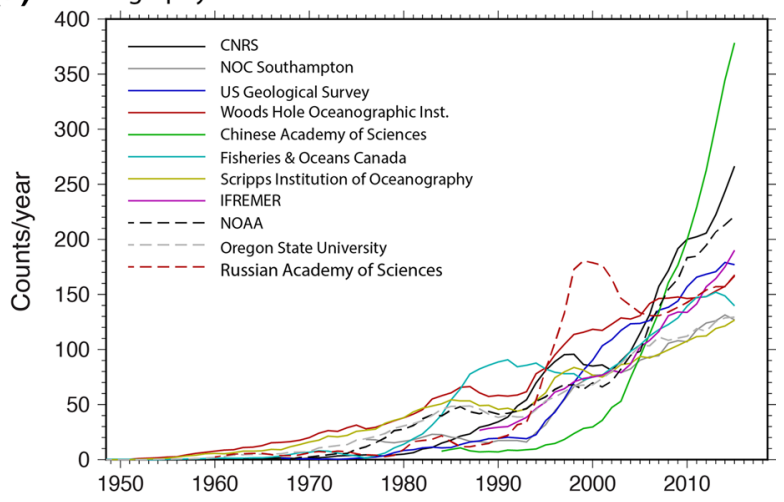

(b) Marine Geoscience

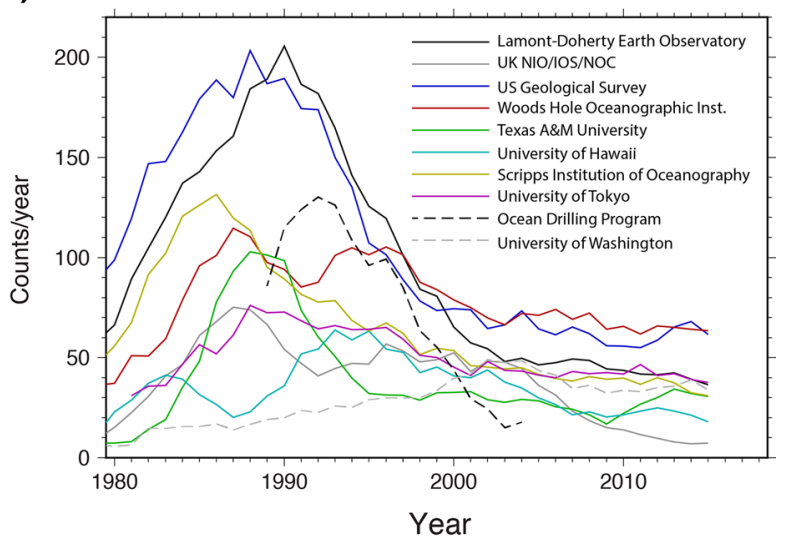

distances (Fig. 5b) with crude oil prices (Fig. 8), suggesting that decisions by vessel operators were largely insensitive to fuel prices.

Global Marine Geoscience publication rates peaked in the late 1980s, less than a decade after oil prices peaked in 1980. Interest by funders in resource availability is a plausible explanation. In the breakdown shown in Fig. 9b, publishing rates peaked in many 
institutions, though at differing times. This might reflect interest from different funders. For example, publication rates of the US Geological Survey (USGS) peaked 2 years before those of Lamont-Doherty Earth Observatory (LDEO). The former was funded directly through the US Department of the Interior, whereas the latter was funded by diverse sources, including the US National Science Foundation (NSF) and Office of Naval Research. The USGS funding is likely to reflect some resource interest from government. Although funding provided by NSF can also reflect government priorities, individual grants are allocated through peer review and NSF may have responded more to priorities set by the science community (there were a number of NSF marine geoscience programmes through the late 1980s and 1990s). Hence, rates for LDEO peaked later. In contrast with the 1980s, the 2008 peak in oil prices was not associated with any subsequent rise in Marine Geoscience publishing rates. This reflects greater concern for the environment (e.g., Mengerink et al. 2014) and presumably less interest in the oceans as repositories of resources.

\section{The Cold War and subsequent development of the marine sciences}

During the Cold War (1946-1989), Oceanography and Marine Geoscience were promoted because of the need to understand aspects of both the water column and seabed (e.g., Anonymous 2019a; Erskine 2013; Lawyer et al. 2001; Raitt and Mouton 1967; Shor 1978). The coincident increase in global publication rates (Fig. 5a) is partly due to direct funding of defense-related research, but can also be attributed partly to indirect funding. For example, some research vessels were acquired by the US Navy for the American academic fleet as a way to promote US marine science (Anonymous 2019b, c). The build up of expertise, knowledge and facilities for defense purposes in the UK (Robinson 2018) supported the development of sidescan sonar for more academic purposes (Rusby et al. 1969; Stubbs 1963) and similar comments can be made about developments in the USA (Spiess and Lonsdale 1982; Spiess and Tyce 1973). Multibeam echo-sounders were first developed for the US Navy, so Cold War defense spending enabled their availability for civilian purposes from the late 1970s (Farr 1980; Renard and Allenou 1979). Given the widespread importance of multibeam sonars to academic marine geoscience over subsequent decades, the Cold War has had a legacy lasting beyond its ending in 1989.

Although global publishing rates in both subject areas increased from 1948 until the end of the Cold War in 1989, they had different exponential gradients and inflection times over that period (Fig. 5). LDEO became important in Marine Geoscience in the 1980s (Fig. 9b). Although organization-specific bibliometric data are not available in Georef before 1980, the developments at LDEO had a leading role in the rapid increase in Marine Geoscience publication rates in the 1960s, either directly (articles by researchers at LDEO) or indirectly through the acquisition of geophysical data and seabed samples. LDEO had only one research vessel in the 1950s (RV Vema) but acquired RVs Conrad and Eltanin in 1962 and those vessels then served to 1989 and 1975, respectively (Anonymous 2019b; Weissel 2019). In contrast, the more subject-diverse Woods Hole Oceanographic Institution and Scripps Institution of Oceanography had a number of research vessels in the 1950s (Anonymous 2019c; Shor 1978). This period also coincides with the lead up to the first expedition of the Deep Sea Drilling Project in 1968 (Ewing 1969), when sites and scientific plans for them needed to be developed. Although only a part of the work done at LDEO was defense-related, a combination of resource and defense interest may help to explain the different publication histories of Oceanography and Marine Geoscience until the mid-1980s. 
From the mid-1980s onwards, global Oceanography and Marine Geoscience publication histories strongly diverged (Fig. 5). As mentioned, changes in attitudes to the oceans as resources and concerns about the environment likely have played strong roles in this. However, the changes of trends in both histories also coincide with the 1985 rise to power of Mikael Gorbachev in the Soviet Union (Matlock 2004), so it is tempting to attribute reduced security concerns to this also.

\section{UK oceanography and marine geoscience}

The UK and global publication rates followed broadly similar trajectories before the 1980s in both Oceanography and Marine Geoscience (Fig. 5a), though the UK's Oceanography publication rates fell behind global rates in the 1960s and 1970s. Robinson (2018) described how the UK's oceanography developed during the Cold War and was funded. He outlined how military requirements gradually gave way to civilian research intended to help the UK's economic problems. With that context, it is tempting to conclude that Marine Geoscience was favoured over Oceanography towards the end of the 1970s as a growing realization of the importance of offshore oil and gas to the UK economy emerged, with the first North Sea oil found in the Forties Field in 1970 (Craig et al. 2018) and first extracted from the Argyll Field in 1975 (Gluyas et al. 2018). The UK joined the DSDP in 1975 and the ODP in 1986 (Anonymous 2007) until the end of the programme in 2007. It had also participated in the DSDP earlier, e.g., leading expedition 12 (Laughton and Bergren 1972). Although research within the DSDP and ODP was primarily blue skies in nature, a realization may have emerged that the UK oil and gas industry would likely benefit from scientific findings, the technologies and analytical methods developed and the education of $\mathrm{PhD}$ students. The decision to join the programmes occurred at times when tax revenues from North Sea oil and gas were rising or imminent in the 1970s and high in the 1980s (Fig. 8). Two notes by J. Bowman within the JOIDES Journal volume 10 (issues 2 and 3) emphasize the importance of the ODP to the UK petroleum industry. The drilling reports also show that UK petroleum companies sent their personnel to assist in the scientific and technical work of the drilling ships at sea. A further factor was the mapping of the USA exclusive economic zone under contract to the USGS (Gardner 1996), under which many publications were jointly published with USGS scientists. Hence publication rates of the UK's Institute of Oceanographic Sciences peaked at about the same time as those of the USGS (Fig. 9b).

Two deviations occur in the UK Oceanography publication rates about their decadal trends. The first in the 1960s presumably relates to the UK's economic problems at that time and shifting priorities (Robinson 2018). A second, subtler deviation occurred in the late 1980s. The UK's Gross Expenditure in Research and Development (GERD) (Fig. 8) declined as a proportion of GDP through the 1980s until the late 1990s. According to Parliamentary Office of Science and Technology (1999), the NERC Marine science budget only modestly increased in real terms over 1985-1989, then abruptly increased by roughly a third in 1989-1990, before decreasing to intermediate values. There is a modest correlation of the Scopus UK Oceanography article publication rates with these funding variations (1985-1997: $R=0.64)$. However, the National Oceanography Centre in Southampton, UK, was opened in 1996 (https://noc.ac.uk/about-us/our-organisation/our-history) and it is unclear how much of the reported NERC funding was associated with that building's development, rather than science. 


\section{UK collaborative publications}

Of the top-10 countries found in the global network analysis of year 2000 publications in Ocean Science and Technology carried out by Dastidar (2004), the same appear in Fig. 2 except for Japan and Russia, whereas Portugal was not in his list of top-25 and China was only 18th. The general correspondence illustrates the role of the UK Oceanography in global networks typical of oceanography (Jappe 2007), though also preferring the regional EU network (Schubert and Glänzel 2006). The increases in Fig. 2 follow general trends in science towards larger publishing networks as research has become more sophisticated and requires greater funding (Frazzetto 2004; Georghiou 1998). The data likely partly reflect preferences driven by EU funding availability (Subramanyam 1983). However, article ratios lying higher than population ratios for most countries in Fig. 3 suggests they are modified by other factors, in particular by the presence of adjacent sea areas (e.g., Denmark, Netherlands, Norway) and therefore natural needs for collaboration due to proximity (Rozwadowski 2004; Zitt et al. 2000). If collaborative preferences followed tendencies for articles per capita to follow GDP per capita (Niu et al. 2014), article ratios in Fig. 3 would be expected to lie closer to population ratios for the developed countries.

The mean numbers of authors on UK Oceanography articles (from 1.7 in 1973 to 5.7 in 2016) lie between more individualistic subjects with less need for equipment such as mathematics [mean author lengths $\sim 1.3$ in 1980 to $>1.9$ after 2000 (Behrens and Luksch 2011)] and subjects involving access to major facilities such as nuclear physics $(<6$ in 1980 to 16 in 2014 (Behrens and Luksch 2011)). Huang (2015) studied author lengths in mathematics, physics and chemistry from 1960 to 2010. The decline in the proportion of single author publications in Oceanography (Fig. 4a) roughly mimics those in physics and chemistry in his analysis, though their percentages have been smaller in the latter two subjects (from peaks of $40 \%$ for physics and $20 \%$ for chemistry in the 1960 s). The maximum numbers of authors in physics has increased in a series of stepped plateaus, reflecting the introduction of new programmes involving major infrastructure, the most recent leading to a publication with $\sim 3000$ authors. The lack of a stepped structure in Oceanography maximum author lengths (Fig. 4c) may have arisen from a greater diversity of international programmes and infrastructure in the field, as well as perhaps a different culture.

As collaboration in Marine Geoscience has been strongly affected by the UK's involvement in international scientific drilling, author maxima typically reflect research arising from drilling expeditions (Fig. 7c). Their doubling time (32.3y) is longer than the $12.7 \mathrm{y}$ doubling time for Oceanography (Fig. 4) because the numbers of scientific berths on the drilling vessels has not changed greatly. Collaborative articles reached extreme proportions of all UK-authored Marine Geoscience articles in $~ 1990$ but have since been generally in decline (Fig. 6), though percentages were still comparable with Oceanography in 2018 (Fig. 2). That decline has mimicked the decline in overall UK Marine Geoscience publication rates, which in turn partly reflects the decline in UK articles in the drilling reports (Fig. 5). This dominance of scientific drilling is also reflected in the organizations of collaborative articles in Marine Geoscience (Table 3), where the top-five organisations are all American. In contrast, four of the Oceanography top-five are European. These changes are suspected to have arisen from funding preferences, with the principal UK funder of Oceanography and Marine Geoscience, the Natural Environmental Research Council, and the EU, preferring environmental over geoscientific research (www.nerc.ac.uk). 
Table 3 Top-five organizations collaborating with UK researchers (\% of all 1938-2018 articles in each field)

\begin{tabular}{lrll}
\hline Marine geoscience & $\%$ & Oceanography & $\%$ \\
\hline Lamont-Doherty Earth Obs. & 18.2 & CNRS (France) & 1.4 \\
Scripps Inst. Ocean. & 12.1 & Woods Hole Ocean. Inst. & 1.0 \\
Ocean Drill. Prog. & 11.9 & Alfred-Wegener Inst. (Ger.) & 0.9 \\
US Geol. Surv. & 10.4 & IFREMER (France) & 0.9 \\
Woods Hole Ocean. Inst. & 9.8 & GEOMAR (Germany) & 0.9 \\
\hline
\end{tabular}

\section{Conclusions}

This analysis has revealed contrasting publication histories for global Oceanography and Marine Geoscience. Publication rates in both subject areas increased rapidly following World War II, with doubling times as short as 6.6y for Oceanography 1969-1980 and 2.3y for Marine Geoscience 1962-1969. However, prominent changes of trend occurred in both subjects in the 1980s, with global Oceanography exponential publishing rate slowing $(t 2=17.0 y$ for $1980-2018)$ and Global Marine Geoscience subsequently declining. This contrast is suggested to have arisen from changing priorities, from spending motivated by the search for resources and defense before the 1990s towards environmental and ecological research in more recent times. The UK's publication rates have followed the global trends, though UK Marine Geoscience experienced a rapid increase in the early 1980s from $4.9 \%$ (average 1960-1980) to $13.2 \%$ of global publishing by 1990 , largely as a result of joining the Deep-Sea Drilling Project and Ocean Drilling Program. Decisions within the UK to join these programmes were likely influenced by the development of North Sea oil and gas during the late 1970s.

Collaborative research in Oceanography with UK researchers has followed global trends, with mean author lengths increasing exponentially (1973-2018: $t 2=23.8 \mathrm{y})$. Maximum author lengths have increased with a shorter doubling time of $12.7 \mathrm{y}$. In Marine Geoscience, median author lengths have increased similarly to the mean Oceanography lengths, but maximum author lengths have increased with a longer doubling time of $32.3 \mathrm{y}$, because most articles with large author lists have been associated with the drilling ships and reflect modestly increasing berthing capacity on them. The importance of the drilling programmes is also reflected in international co-authorships, which generally peaked in Marine Geoscience at around 1990 but subsequently declined. In contrast, within Oceanography collaborative articles with English-speaking countries (USA, Canada, Australia) and with European countries with shared seas have generally increased as a share of total UK Oceanography publications over the past 60 years. UK Oceanography publications with Chinese researchers has increased rapidly from the mid-2000s, doubling in only 4 years (2014-2018).

Global Marine Geoscience publishing rates were strongly correlated with track-line distances of marine geophysical data lodged at the National Geophysical Data Center for the period up to 1972 , but were negatively correlated after 1972 . This indicates a major change in the efficiency with which Marine Geoscience research was carried out, with on average $2210 \mathrm{~km} /$ article before 1972, subsequently declining to only $323 \mathrm{~km} /$ article by 1995 . Similar correlations were found with seabed samplings, with on average 8.9 seabed samples per article published 1960-1972, later declining to on average 1.9 samples per article 1979-1995. These suggest a change in efficiency to the later period with greater use of preexisting data and samples, and more sophisticated equipment, sampling and data analysis, 
which ultimately yielded greater information compared with the seatime deployed. For Oceanography, article publication rates were correlated with casts of temperature and salinity but that changed in about 1990, when a greater diversity of measuring methods emerged (gliders, autonomous floats, moored systems). However, that change was associated with a deceleration in global publication rates in Oceanography.

Acknowledgements I thank Tony Watts, Christine Peirce, Bart van Dongen and Sam Shaw for discussions. Helpful comments from two anonymous reviewers provoked the extended analysis of correlations with marine field data and a thorough revision of the article. Figures shown in this article were created with the free software of Wessel and Smith (1991).

Open Access This article is licensed under a Creative Commons Attribution 4.0 International License, which permits use, sharing, adaptation, distribution and reproduction in any medium or format, as long as you give appropriate credit to the original author(s) and the source, provide a link to the Creative Commons licence, and indicate if changes were made. The images or other third party material in this article are included in the article's Creative Commons licence, unless indicated otherwise in a credit line to the material. If material is not included in the article's Creative Commons licence and your intended use is not permitted by statutory regulation or exceeds the permitted use, you will need to obtain permission directly from the copyright holder. To view a copy of this licence, visit http://creativecommons.org/licenses/by/4.0/.

\section{References}

Aksnes, D. W., \& Browman, H. I. (2016). An overview of global research effort in fisheries science. ICES Journal of Marine Science, 73, 1004-1011.

Anonymous. (2007). Ocean drilling program, final technical report 1983-2007. In Consortium for ocean leadership, Lamont-Doherty earth observatory (p. 68). Texas A\&M University.

Anonymous. (2019a). Office of naval research. https://en.wikipedia.org/wiki/Office_of_Naval_Research. Accessed 20 July 2019.

Anonymous. (2019b). History of WHOI ships. https://www.whoi.edu/multimedia/v-history-of-whoi-ships/. Accessed 20 July 2019.

Anonymous. (2019c). Lamont's research vessels: A look back- and forward (1953-2006). https://www.ldeo. columbia.edu/research/office-of-marine-operations/history. Accessed 20 July 2019.

Arrhenius, G. A. (1963). Pelagic sediments. In M. N. Hill (Ed.), The sea (pp. 655-727). New York: Wiley.

Behrens, H., \& Luksch, P. (2011). Mathematics 1868-2008: A bibliometric analysis. Scientometrics, 86, $179-194$.

Bjurström, A., \& Polk, M. (2011). Climate change and interdisciplinarity: A co-citation analysis of IPCC third assessment report. Scientometrics, 87, 525-550.

Bond, R. L. (1999). A core a day keeps 'doc' happy. In L. Lippsett (Ed.), Lamont-Doherty earth observatory: Twelve perspectives on the first fifty years (1949-1999) (pp. 75-84). New York: Columbia Univ. Press.

Bornmann, L., \& Mutz, R. (2015). Growth rates of modern science: A bibliometric analysis based on the number of publications and cited references. J. Assoc. Inform. Science Technol., 66, 2215-2222.

Bosman, J., Mourik, I., Rasch, M., Sieverts, E., Verhoeff, H. (2006). Scopus reviewed and compared: the coverage and functionality of the citation database Scopus, including comparisons with Web of Science and Google Scholar. Utrecht: Utrecht University Library. https://dspace.library.uu.nl/handl e/1874/18247. Accessed 18224/18212/12018.

Boyer, T. P., Baranova, O. K., Coleman, C., Garcia, H. E., Grodsky, A., Locarnini, R. A., Mishonov, A. V., Paver, C. R., Reagan, J. R., Seidov, D., Smolyar, I. V., Weathers, K. W., \& Zweng, M. M. (2018). World ocean database 2018. In: A. V. Mishonov TE (ed) NOAA Atlas NESDIS 87 (p. 207).

Burnham, J. F. (2006). Scopus database: A review. Biomedical Digital Libraries. https://doi. org/10.1186/1742-5581-1183-1181.

Chiu, W.-T., \& Ho, Y.-S. (2007). Bibliometric analysis of tsunami research. Scientometrics, 73, 3-17.

Craig, J., Gerali, F., MacAulay, F., \& Sorkhabi, R. (2018). The history of the European oil and gas industry (1600s-2000s). In J. Craig, F. Gerall, F. MacAulay, \& R. Sorkhabi (Eds.), history of the European oil and gas industry (pp. 1-24). London: Geological Society Special Publication.

Dastidar, P. G. (2004). Ocean science and technology research across the countries: A global scenario. Scientometrics, 59, 15-27. 
Emiliani, C. (1955). Pleistocene temperatures. Journal of Geology, 63, 538-578.

Erskine, F. T. (2013). A history of the Acoustics Division of the Naval Research Laboratory: The first eight decades 1923-2008. Washington, D.C.: Naval Research Laboratory.

Ewing, M., et al. (1969). Initial reports of the deep-sea drilling project, V1, Washington: US Government Printing Office.

Farr, H. K. (1980). Multibeam bathymetric sonar: SeaBeam and hydrochart. Marine Geodesy, 4, 77-93.

Fisher, R. L., \& Sclater, J. G. (1983). Tectonic evolution of the Southwest Indian Ocean since the Mid-Cretaceous: Plate motions and stability of the pole of Antarctica/Africa for at least $80 \mathrm{Myr}$. Geophysical Journal of the Royal Astronomical Society, 73, 553-576.

Frazzetto, G. (2004). The changing identity of the scientist. European Molecular Biology Organization Reports, 5, 18-20.

Gardner, J. V. (1996). Introduction. In: Gardner, J. V., Field, M. E., \& Twichell, D. C. (Eds.), Geology of the United States' seafloor: The view from GLORIA (pp. 1-4).

Georghiou, L. (1998). Global cooperation in research. Research Policy, 27, 611-626.

Gluyas, J., Tang, L., \& Jones, S. (2018). Argyll field: The first oil field to be developed on the UK Continental Shelf. In J. Craig, F. Gerall, F. MacAulay, \& R. Sorkhabi (Eds.), History of the European oil and gas industry (pp. 77-93). London: Geological Society Special Publication.

Gower, J. F. R. (2010). Oceans from space, a once-a-decade review of progress: Satellite oceanography in a changing world. New York

Hein, J. R., \& Koschinsky, A. (2014). Deep-ocean ferromanganese crusts and nodules. In: Treatise on geochemistry, 2nd ed. (pp. 273-291). Elsevier.

Huang, D.-W. (2015). Temporal evolution of multi-author papers in basic sciences from 1960 to 2010. Scientometrics, 105, 2137-2147.

Jappe, A. (2007). Explaining international collaboration in global environmental change research. Scientometrics, 71, 367-390.

Jarić, I., Cvijanović, G., Knežević-Jarić, J., \& Lenhardt, M. (2012). Trends in fisheries science from 2000 to 2009: A bibliometric study. Reviews of Fisheries Science, 20, 70-79.

Laughton, A. S., Bergren, W. A., et al. (1972). Initial reports of the deep-sea drilling project, V12. Washington: US Government Printing Office.

Lawyer, L. C., Bates, C. C., \& Rice, R. B. (2001). Geophysics in the affairs of mankind: A personalized history of exploration geophysics (2nd ed., p. 429). Tulsa: Society of Exploration Geophysicists.

Liao, J., \& Huang, Y. (2014). Global trend in aquatic ecosystem research from 1992 to 2011. Scientometrics, 98, 1203-1219.

Liu, X., Zhan, F. B., Hong, S., Niu, B., \& Liu, Y. (2012). A bibliometric study of earthquake research: 1900-2010. Scientometrics, 92, 747-765.

Matlock, J. F. (2004). Reagan and Gorbachev: How the cold war ended (p. 369). New York: Random House.

McKenzie, D. P., \& Parker, R. L. (1967). The North Pacific: An example of tectonics on a sphere. Nature, 216, 1276-1280.

Mengerink, K. J., Van Dover, C. L., Ardron, J., Baker, M., Escobar-Briones, E., Gjerde, K., et al. (2014). A call for deep-ocean stewardship. Science, 344, 696-698.

Miller, I., \& Freund, J. E. (1965). Probability and statistics for engineers (p. 432). New Jersey: Prentice-Hall.

Niu, B., Hong, S., Yuan, J., Peng, S., Wang, Z., \& Zhang, X. (2014). Global trends in sediment-related research in earth science during 1992-2011: A bibliometric analysis. Scientometrics, 98, 511-529.

Parliamentary Office of Science and Technology. (1999). Marine science and technology (p. 20). POST Report 128.

Parsons, B. E., \& Sclater, J. G. (1977). An analysis of the variation of ocean floor bathymetry and heat flow with age. Journal Geophysical Research, 82, 803-827.

Prell, W. L., Gardner, J. V. (1982). Init. Repts. deep-sea drilling project (vol. 68). Washington D.C.: US Government Prining Office.

Raitt, H., \& Mouton, B. (1967). Scripps institution of oceanography: First fifty years. Los Angeles: The Ward Ritchie Press.

Renard, V., \& Allenou, J. P. (1979). SeaBeam multi-beam echosounding in "Jean Charcot", description, evaluation and first results. The International Hydrographic Review, 56, 35-67.

Rey-Rocha, J., \& Martín-Sempere, M. J. (2004). Patterns of the foreign contributions in some domestic vs. international journals on Earth Sciences. Scientometrics, 59, 95-115.

Riley, J. P., \& Sinhaseni, P. (1958). Chemical composition of three manganese nodules from the Pacific Ocean. Journal of Marine Research, 17, 466-482. 
Robinson, S. A. (2018). Ocean science and the British Cold War state. Switzerland: Palgrave Macmillan.

Rozwadowski, H. M. (2004). Internationalism, environmental necessity, and national interest: Marine science and other sciences. Minerva, 42, 127-149.

Rusby, J. S. M., Dobson, R., Edge, R. H., Pierce, F. E., \& Somers, M. L. (1969). Records obtained from the trials of a long range side-scan sonar (GLORIA Project). Nature, 223, 125-126.

Schubert, A., \& Glänzel, W. (2006). Cross-national preference in co-authorship, references and citations. Scientometrics, 69, 409-428.

Shor, E. N. (1978). Scripps Institution of Oceanography: Probing the oceans 1936 to 1976 (p. 502). San Diego: Tofua Press.

Spatafora, N., \& Tytell, I. (2009). Commodity terms of trade: The history of booms and busts, WP/09/205 (p. 34). International Monetary Fund.

Spiess, F. N., \& Lonsdale, P. F. (1982). Deep tow rise crest exploration techniques. Marine Technology Society Journal, 16(3), 67-74.

Spiess, F. N., \& Tyce, R. C. (1973). Marine physical laboratory deep tow instrumentation system. San Diego: University of California, Marine Physical Laboratory of the Scripps Institution of Oceanography.

Stubbs, A. R. (1963). Identification of patterns on asdic records. International Hydrographic Review Monoco, 400(2), 53-68.

Subramanyam, K. (1983). Bibliometric studies of research collaboration: A review. Journal of Information Science, 6, 33-38.

Summerhayes, C. P. (1998). Ocean resources. In C. P. Summerhayes \& S. A. Thorpe (Eds.), Oceanography: An illustrated guide (pp. 314-337). Boca Raton: Manson Publishing.

Theyer, F., Vincent, E., \& Mayer, L. A. (1989). Sedimentation and paleoceanography of the central equatorial Pacific. In E. L. Winterer, D. M. Hussong, \& R. W. Decker (Eds.), The Eastern Pacific Ocean and Hawaii (pp. 347-372). Boulder: Geological Society of America.

van Leeuwen, T. N., Moed, H. F., Tijssen, R. J. W., Visser, M. S., \& van Raan, A. F. J. (2001). Language biases in the coverage of the science citation index and its consequences for international comparisons of national research performance. Scientometrics, 51, 335-346.

Vine, F. J., \& Matthews, D. H. (1963). Magnetic anomalies over oceanic ridges. Nature, 199, 947-949.

Wagner, C. S., \& Leydesdorff, L. (2003). Seismology as a dynamic, distributed area of scientific research. Scientometrics, 58, 91-114.

Wang, H., Liu, M., Hong, S., \& Zhuang, Y. (2013). A historical review and bibliometric analysis of GPS research from 1991-2010. Scientometrics, 95, 35-44.

Wang, M.-H., Yu, T.-C., \& Ho, Y.-S. (2010). A bibliometric analysis of the performance of Water Research. Scientometrics, 84, 813-820.

Wang, Y., Tan, S., Ma, Y., Zhao, X., Wang, Z., Chu, Z., et al. (2016). Application of bibliometrics in analysis of output differences among countries under International Ocean Discovery Program. Scientometrics, 109, 447-462.

Weissel, J. (2019). A brief history of Marine Geology and Geophysics at Lamont. https://www.ldeo.colum bia.edu/research/marine-geology-geophysics/mg-g-history. Accessed 16 January 2019.

Wessel, P., \& Chandler, M. T. (2011). The spatial and temporal distribution of marine geophysical surveys. Acta Geophysica, 59, 55-71.

Wessel, P., \& Smith, W. H. F. (1991). Free software helps map and display data. Eos, Transactions, American Geophysical Union, 72, 441.

Zhang, W., Qian, W., \& Ho, Y.-S. (2009). A bibliometric analysis of research related to ocean circulation. Scientometrics, 80, 305-316.

Zhou, F., Guo, H.-C., Ho, Y.-S., \& Wu, C.-Z. (2007). Scientometric analysis of geostatistics using multivariate methods. Scientometrics, 73, 265-279.

Zhuang, Y., Liu, X., Nguyen, T., He, Q., \& Hong, S. (2013). Global remote sensing research trends during 1991-2010: A bibliometric analysis. Scientometrics, 96, 203-219.

Zitt, M., Bassecoulard, E., \& Okubo, Y. (2000). Shadows of the past in international cooperation: Collaboration profiles of the top five producers of science. Scientometrics, 47, 627-657. 


\section{Affiliations}

Neil C. Mitchell ${ }^{1}$ D

$\square$ Neil C. Mitchell

neil.mitchell@manchester.ac.uk

1 Department of Earth and Environmental Sciences, University of Manchester, Manchester M13 9PL, UK 